\title{
O método estrutural-diferencial: aplicação da adaptação de Herzog e Olsen para a microrregião de Maringá frente à economia paranaense 1994/ 20081
}

Structural-differential method: implementation of the Herzog and Olsen adaptation to Maringá microregion against the State of Paraná 1994/ 2008

Carlos Alberto Gonçalves J unior² Rinaldo Aparecido Galete 3

\begin{abstract}
Resumo: O presente artigo tem como objetivo analisar a microrregião de Maringá a partir do método estrutural-diferencial frente ao estado do Paraná. A microrregião apresentou dinamismo principalmente nos setores de confecção de artigos do vestuário e acessórios e produção de alimentos e bebidas, porém não apresentou esse dinamismo em setores estratégicos como fabricação de equipamentos de informática, materiais eletrônicos e veículos automotores. Nesse contexto torna-se necessária uma atenção especial para esta constatação no sentido de direcionamento das políticas públicas no intuito de estimular esse dinamismo.
\end{abstract}

Palavras-Chave: Método Estrutural-diferencial; Economia regional; Desenvolvimento econômico.

Abstract: This paper aims to analyze the microregion of Maringá using the shift-share method against the state of Parana. The microregion showed dynamism mainly in the manufacture of articles of clothing and accessories and food and drinks production, however it did not show this same dynamism in strategic sectors such as manufacturing of special computer equipment, electronic materials and automobiles. In this context it is necessary attention to this finding in the sense of the direction of public policy in order to foster this dynamism.

Key Words: Shift-share method; Regional economy; Economic development.

JEL: R11.

\section{Introdução}

A análise do desenvolvimento regional tem sido realizada sob duas principais abordagens teóricas, onde o desenvolvimento se deve a fatores endógenos ou exógenos à região. Na abordagem da Teoria dos Pólos, uma determinada região cresce por forças internas, por sua vez, pela Teoria da Base, as forças são externas à região.

As inovações realizadas pela chamada indústria motriz aumentam a sua competitividade, o que se reflete nas atividades ligadas, assim, a região torna-se exportadora, como resultado de seu próprio desenvolvimento.

Alternativamente, variações da demanda externa afetam a economia local. As indústrias da área adaptam-se rapidamente e expandem a produção, gerando efeitos de encadeamento no conjunto do sistema nacional de regiões. Destarte, o

\footnotetext{
${ }^{1}$ Artigo recebido em dezembro de 2010 e aprovado em fevereiro de 2011.

2 Graduado em economia e pós-graduado em estatística aplicada pela UEM. Mestre em desenvolvimento regional e agronegócio pela UNIOESTE/Campus Toledo. Professor efetivo do curso de ciências econômicas da UNIOESTE/ Campus Toledo. E-mail: carlosalbertojr@hotmail.com

${ }^{3}$ Graduado em Ciências Econômicas e especialista em Estatística Aplicada pela UEM. Mestre em Economia Social e do Trabalho pela UNICAMP. Professor titular da Faculdade Alvorada de Tecnologia e Educação de Maringá. Professor titular do Centro de Ensino Superior de Maringá. E-mail: rgalete@uol.com.br
} 
crescimento regional torna-se impulsionado tanto por fatores internos como por fatores externos à região.

Entre os vários métodos utilizados na análise regional, o Método EstruturalDiferencial (Shift-Share) pode ser utilizado para captar esse comportamento da dinâmica regional. Este método procura descrever o crescimento econômico de uma região em termos de sua estrutura produtiva.

No presente trabalho, o objetivo principal é fazer uma análise da estrutura produtiva da indústria de transformação da Microrregião de Maringá (PR) frente à economia paranaense no período compreendido entre 1994 a 2008, com base nos dados de vínculos empregatícios contidos na Relação Anual de Informações Sociais RAIS, disponibilizadas pelo Ministério do Trabalho e Emprego - MTE. As informações da RAIS foram processadas em nível de divisões (02 dígitos) da Classificação Nacional de Atividades Econômicas - C.N.A.E.

Afora esta introdução, o presente artigo está assim dividido: a seção dois apresenta, sumariamente, o Método Estrutural-Diferencial, as suas principais limitações metodológicas e as principais modificações do método. Apresenta ainda uma caracterização da Microrregião de Maringá (MRM), sua estrutura industrial e do emprego, comparativamente ao estado do Paraná. Na seção três são discutidos os principais resultados empíricos. A seção quatro apresenta as considerações finais.

\section{Revisão Teórica e Procedimentos Metodológicos}

É fato que algumas regiões crescem mais que outras por dinamismos diferentes, sejam locais ou nacionais, além disso, algumas regiões com desempenho abaixo da média nacional podem possuir setores com maior dinamismo econômico. Identificar esses setores pode ser de grande valia, principalmente para o direcionamento de políticas públicas que possam alavancar estes setores dinâmicos o que permitiria aumentar o desempenho da região como um todo.

Um método comumente utilizado para identificar os setores dinâmicos de uma região frente a outra em que está contida é o estrutural-diferencial, ou shift-share, que será abordado a seguir.

\subsection{0 método estrutural-diferencial}

Segundo Souza (2009) o crescimento regional deve-se a fatores regionais e nacionais. Os fatores regionais são gerados pelas peculiaridades internas, que proporcionam vantagens locacionais para determinados setores. Já os fatores nacionais são determinados pelo fato de existir na economia local atividades que nacionalmente apresentam dinamismo.

De acordo com Simões (2005) o método Estrutural Diferencial ou shift-share descreve o crescimento de uma região baseado em sua estrutura de produção. $\mathrm{O}$ método procura decompor os componentes do crescimento numa análise descritiva da estrutura produtiva.

Para Haddad (1989) o método não explica o crescimento regional, mas procura identificar os componentes deste crescimento. São relações contábeis e definições que não apresentam nenhuma hipótese de comportamento entre as variáveis. 
Parte-se da constatação de que há diferenças setoriais e regionais no que diz respeito ao crescimento entre dois períodos de tempo. Esta diferença pode ser causada pela existência de setores mais dinâmicos ou menos dinâmicos na composição da estrutura produtiva de uma região ou por uma maior ou menor participação na distribuição regional de uma variável econômica básica, ocorrendo ou não setores mais ou menos dinâmicos.

De acordo com Souza (2009) a variável econômica básica preferível para a análise é o valor da produção, pois refletem melhor a contribuição de cada um dos fatores no processo produtivo, no entanto, tem-se utilizado com freqüência dados de emprego na análise, pois são freqüentemente disponibilizados no nível regional.

Quando utiliza-se dados de emprego na análise é necessário pressupor que não existem diferenças significativas na produtividade da mão-de-obra dos setores analisados e também entre as regiões consideradas, sem essa pressuposição, uma região poderia apresentar crescimento superior às outras pela maior produtividade da mão-de-obra e não por vantagens locacionais ou outros dinamismos que o método busca identificar.

Para Azzoni (1997) o método estrutural-diferencial decompõe o desempenho de uma região em um período em três componentes, variação regional, variação estrutural e variação diferencial, que serão sucintamente abordadas em seguida.

A variação regional é aquela que teria ocorrido se a região crescesse à taxa média nacional de todos os setores da economia, também chamada de taxa teórica. A variação estrutural, também chamada de variação proporcional representa a variação no crescimento (positiva ou negativa) que uma região poderia ter como resultado de sua composição industrial, isto é, a participação relativa dos setores dinâmicos ou de crescimento lento.

De acordo com Haddad (1989) A variação estrutural será positiva quando a região tiver se especializado em setores da economia nacional que apresentam altas taxas de crescimento, e negativa quando a região se especializar em setores que na esfera nacional apresentarem baixas taxas de crescimento.

A variação diferencial, ou competitiva, indica o montante positivo (ou negativo) de crescimento que a região j conseguiria pelo fato de a taxa de crescimento em determinados setores ter sido maior (ou menor) nesta região do que na média nacional.

Em resumo, a variação diferencial, segundo Azzoni (1997) é a diferença entre a variação regional e a estrutural, ou seja, a diferença entre o crescimento efetivo em uma determinada região e seu crescimento hipotético, que é estimado pela média do crescimento nacional.

Assumindo o emprego como variável básica para a utilização do modelo estrutural-diferencial ou shift-share no presente artigo, a equação (1) apresenta a variação real do emprego do setor i na região j $\left(E_{i j}^{t}-E_{i j}^{0}\right)$ como sendo igual a variação teórica $\left(E_{i j}^{0} e\right)$, adicionadas as variações estrutural $E_{i j}^{o}\left(e_{i}-e\right)$ e diferencial $E_{i j}{ }^{0}\left(e_{i j}-e_{i}\right)$.

$$
\left(E_{i j}^{t}-E_{i j}^{0}\right)=\left(E_{i j}^{0} e\right)+E_{i j}^{o}\left(e_{i}-e\right)+E_{i j}{ }^{0}\left(e_{i j}-e_{i}\right)
$$

Onde ( $E_{i j}^{0}$ ) é o emprego inicial do setor i na regiãoj; $\left(E_{i j}^{t}\right)$ é o emprego final do setor i na regiãoj; ( $e$ ) é a taxa de crescimento do emprego total nacional; $\left(e_{i}\right.$ ) é a taxa de crescimento nacional do emprego no setor $\mathrm{i}$. 
Segundo Souza (1997) se a variação real do emprego do setor i na região j for superior a variação teórica, significa que o emprego do setor i da região j cresceu mais que a média nacional e que existem elementos dinâmicos internos ou externos atuando na região de forma positiva. Se a variação real for menor que a teórica, significa que o setor i da região j está sem dinamismos específicos por estar crescendo abaixo da média nacional.

Com isso, pode-se determinar o efeito total como sendo a diferença entre a variação real e a variação teórica do emprego:

$$
T_{i j}=\left(E_{i j}^{t}-E_{i j}^{0}\right)-\left(E_{i j}^{0} e\right)=E_{i j}^{o}\left(e_{i}-e\right)+E_{i j}{ }^{0}\left(e_{i j}-e_{i}\right)
$$

Onde $T_{i j}$ é a variação líquida setorial.

O efeito total será positivo quando ambos os efeitos, estrutural e diferencial forem positivos, ou quando um deles apresentar um valor que supere a magnitude negativa do outro.

Quando o efeito estrutural é positivo significa que o setor i da economia nacional cresceu mais do que a economia do país e a região j terá esse dinamismo positivo quando o setor i estiver bem representado na economia da região.

Um efeito diferencial positivo mostra que o crescimento do setor i na região j foi superior ao crescimento desse setor no nível nacional, seja ela dinâmica ou não.

\subsubsection{Aperfeiçoamento do modelo}

O modelo estrutural-diferencial básico, conforme exposto na seção anterior, apresenta algumas dificuldades e limitações. De acordo com Haddad (1989) um dos principais defeitos ou limitações dessa análise é que não considera mudanças na estrutura de emprego das regiões durante o período de análise, isto é, entre o ano base e o ano final.

Quanto mais longo for o período mais as mudanças não consideradas serão importantes, o que pode gerar um viés na análise dos efeitos. Destarte, de acordo com Souza (2009), para eliminar esse problema Stilwell (1969), propõe o cálculo da variação proporcional revertida ( $R i j$ ), onde as taxas de crescimento são revertidas para serem ponderadas com o emprego final $\left(E_{i j}^{t}\right)$ e não com o inicial, conforme mostra a equação 3.

$$
R_{i j}=E_{i j}^{t}\left(1 / e-1 / e_{i}\right)
$$

Se a variação proporcional revertida for maior que a variação proporcional calculada, ou seja, se $R_{i j}=E_{i j}^{t}\left(1 / e-1 / e_{i}\right)>E_{i j}^{o}\left(e_{i}-e\right)$, significa que a estrutura do emprego da região se modificou aumentando a especialização em setores dinâmicos. Se for menor, a modificação estrutural não foi forte em setores dinâmicos, ou simplesmente não ocorreu.

Outra limitação do método estrutural-diferencial é a dependência dos efeitos estrutural e diferencial do emprego no ano base, ou seja, estes efeitos estão entrelaçados. Assim, o efeito diferencial não mede apenas o que se espera que ele meça. De acordo com Haddad (1989), entre os trabalhos que procuram superar este problema está o de Esteban-Marquillas (1972). Neste trabalho os autores propõem uma reformulação da equação $E_{i j}{ }^{0}\left(e_{i j}-e_{i}\right)$ introduzindo o emprego esperado ou 
homotético $\left(E_{i j}^{0} *\right)$ em vez do emprego efetivo inicial $\left(E_{i j}^{0}\right)$. O cálculo do emprego esperado no período inicial é apresentado pela equação 4.

$$
E_{i j}^{0 *}=E_{j}^{0}\left(E_{i}^{0} / E^{0}\right)
$$

Onde, $E_{j}^{0}$ é o emprego total da região j no ano base; $E_{i}^{0}$ é o emprego total do setor no nível nacional, no ano base e $E^{0}$ o emprego total nacional do ano base. Conforme mostra a equação 4 , o emprego esperado do setor i da região j é definido como aquele que guarda a mesma proporção da economia.

De acordo com Souza (2009), introduzindo o emprego esperado no lugar do emprego efetivo na equação do efeito diferencial Esteban-Marquillas (1972) procuraram eliminar da posição diferencial ou competitiva a influência estrutural. Se for utilizado o emprego homotético para calcular o efeito diferencial, este fica sem a influência do efeito proporcional, pois o coeficiente de especialização será igual a zero em todos os setores. A proposição de Estaban-Marquillas (1972) está apresentada na equação 5 .

$$
D^{\prime}=E_{i j}^{0} *\left(e_{i j}-e_{i}\right)
$$

Segundo Haddad (1989) Esteban-Marquillas (1972) também introduzem o efeito de alocação $\left(A_{i j}\right)$, ao lado dos efeitos estrutural e diferencial, para analisar os componentes do crescimento regional. O efeito alocação é a influência estrutural do dinamismo diferencial, ou seja a diferença entre o efeito diferencial tradicional $\left(D_{i j}\right) \mathrm{e}$ o efeito diferencial modificado $\left(D_{i j}^{\prime}\right)$.

$$
A_{i j}=\left(E_{i j}^{0}-E_{i j}^{0 *}\right)\left(e_{i j}-e_{i}\right)
$$

O efeito alocação indica se a região é especializada $\left(E_{i j}^{0}>E_{i j}^{0} *\right)$ e quais setores apresentam melhores vantagens competitivas $\left(e_{i j}>e_{i}\right)$

O Quadro 1 resume as possíveis definições que podem ser obtidas através da análise do efeito alocação

Quadro 1- Sinais dos possíveis efeitos alocação

\begin{tabular}{|l|c|c|c|}
\hline \multicolumn{1}{|c|}{ Definição } & $\begin{array}{c}\text { Efeito Alocação } \\
A_{i j}\end{array}$ & $\begin{array}{c}\text { Especialização } \\
\left(E_{i j}^{0}-E_{i j}^{0 *}\right)\end{array}$ & $\begin{array}{c}\text { Vantagem } \\
\text { competitiva } \\
\left(e_{i j}-e_{i}\right)\end{array}$ \\
\hline Desvantagem competitiva especializada & - & + & - \\
\hline Desvantagem competitiva não especializada & + & - & - \\
\hline Vantagem competitiva não especializada & - & - & + \\
\hline Vantagem competitiva especializada & + & + & + \\
\hline Vant/desv. Comp. c/ mesma estrutura nacional & 0 & 0 & \pm \\
\hline Neutralidade compet. Espec./não especializada & 0 & \pm & 0 \\
\hline
\end{tabular}

Fonte: Souza (2009) adaptado de Herzog e Olsen (1977).

As regiões mais dinâmicas são as que possuem vantagem competitiva especializada, isto é, o setor i encontra-se bem representado na microrregião e cresce mais na microrregião que no estado. Um efeito alocação positivo pode indicar duas situações: (1) que a microrregião é especializada na produção do setor i (+) e que esse setor está crescendo mais na microrregião que no estado (+); (2) ou que esse setor 
está crescendo menos do que a média do estado (-) e que a região não é especializada nesse setor (-).

O efeito alocação negativo pode significar (1) que a microrregião não é especializada na produção do setor i (-), mas esse setor cresce mais na microrregião que no estado (+); (2) que a microrregião é especializada na produção do setor i (+), no entanto, esse setor cresce menos na microrregião que no estado.

O efeito alocação nulo pode significar que (1) houve vantagem ou desvantagem competitiva com o setor i da microrregião guardando a mesma estrutura do estado ou (2) neutralidade competitiva especializada ou não especializada.

Com a contribuição de Esteban-Marquillas, a equação para a variação real do emprego fica decomposta em quatro variações, conforme mostra a equação 7:

$$
\left(E_{i j}^{0}-E_{i j}^{t}\right)=E_{i j}^{0} e+E_{i j}^{0}\left(e_{i}-e\right)+E_{i j}^{0} *\left(e_{i j}-e_{i}\right)+\left(E_{i j}^{0}-E_{i j}^{0 *}\right)\left(e_{i j}-e_{i}\right)
$$

Onde: $\left(E_{i j}^{0}-E_{i j}^{t}\right)$ é a variação real; $E_{i j}^{0} e$ é a variação teórica; $E_{i j}^{0}\left(e_{i}-e\right)$ é a variação estrutural; $E_{i j}^{0} *\left(e_{i j}-e_{i}\right)$ é a variação diferencial pura e $\left(E_{i j}^{0}-E_{i j}^{0 *}\right)\left(e_{i j}-e_{i}\right)$ é a alocativa.

Esteban-Marquillas (1972) propõem uma solução para o problema dos efeitos diferencial e estrutural estarem entrelaçados, mas ainda continua-se com a limitação de ponderação das taxas pelo emprego no ano base $E_{i j}^{0}$. Com isso, um setor não especializado no ano base, poderá vir a sê-lo no ano terminal, o que altera a interpretação desse efeito, independente do valor da vantagem competitiva.

Herzog e Olsen (1977) propõem o efeito alocação modificado $A_{i j}^{\prime}$ com a inclusão do emprego terminal $E_{i j}^{t}$ e do emprego teórico terminal $E_{i j}^{t} *$, no intuito de eliminar a o efeito mudança estrutural do período.

$$
A_{i j}^{\prime}=\left[\left(E_{i j}^{t}-E_{i j}^{t} *\right)-\left(E_{i j}^{0}-E_{i j}^{0} *\right)\right]\left(e_{i j}-e_{i}\right)
$$

Com a mudança no efeito alocação, faz-se necessária uma mudança no cálculo do efeito diferencial puro, indicada por Esteban-Marquillas (1972). Destarte, HerzogOlsen (1977) propõem o efeito diferencial puro modificado $D_{i j}^{\prime \prime}$ como sendo:

$$
D_{i j}^{\prime \prime}=D_{i j}^{\prime}+A_{i j}-A_{i j}^{\prime}
$$

Substituindo os termos da equação 9 pelas respectivas equações já apresentadas:

$D_{i j}^{\prime \prime}=E_{i j}^{o} *\left(e_{i j}-e_{i}\right)+\left(E_{i j}^{0}-E_{i j}^{0} *\left(e_{i j}-e_{i}\right)-\left(E_{i j}^{t}-E_{i j}^{t} *-E_{i j}^{0}+E_{i j}^{o *}\right)\left(e_{i j}-e_{i}\right)\right.$

Colocando $\left(e_{i j}-e_{i}\right)$ em evidência:

$D_{i j}^{\prime \prime}=\left(E_{i j}^{o} *+E_{i j}^{0}-E_{i j}^{0} *-E_{i j}^{t}+E_{i j}^{t} *+E_{i j}^{0}-E_{i j}^{o} *\right)\left(e_{i j}-e_{i}\right)$

Agrupando os termos semelhantes:

$D_{i j}^{\prime \prime}=\left(2 E_{i j}^{0}-E_{i j}^{t}+E_{i j}^{t} *-E_{i j}^{o *}\right)\left(e_{i j}-e_{i}\right)$

Finalmente tem-se a Variação Líquida Total - $V L T_{i j}$ do emprego no setor i da região j. O $V L T_{i j}$ é o resultado da soma entre o efeito estrutural $E_{i j}^{o}\left(e_{i}-e\right)$ - ainda ponderado pelo ano base - com o efeito diferencial puro modificado representado pela equação 12 e o novo efeito alocação representado pela equação 8, conforme segue: 


$$
V L T_{i j}=E_{i j}^{o}\left(e_{i}-e\right)+\left(2 E_{i j}^{0}-E_{i j}^{t}+E_{i j}^{t *}-E_{i j}^{o *}\right)\left(e_{i j}-e_{i}\right)+\left(E_{i j}^{t}-E_{i j}^{t} *-E_{i j}^{0}+E_{i j}^{0 *}\right)\left(e_{i j}-e_{i}\right)
$$

Originalmente nas aplicações do método estrutural-diferencial tem-se utilizado o emprego, em especial o emprego industrial, como variável base. Entretanto, principalmente depois dos últimos desenvolvimentos metodológicos, o método tem sido aplicado em uma ampla área de estudos, contribuindo para os mais distintos objetivos acadêmicos.

Ferreira \& Mendes (2003) utilizaram o método para analisar os impactos de políticas públicas de fomento. Cavalcante; Crocco e Brito (2005) procuraram analisar o aspecto financeiro do desenvolvimento regional. Albuquerque e Pinheiro (1980) quantificaram os fatores que mais influenciaram na produção agrícola. Já Rippel \& Lima (2008) analisaram os fatores diferenciais e estruturais que influenciam na localização da população urbana e rural.

Além disso, Scalabrin \& Alves (2002) aplicaram o método shift-share na análise da geração de valor das empresas brasileiras com ações em bolsa.

Expostos os passos utilizados na análise pelo método shift-share ou estrutural diferencial e suas possíveis aplicações, a próxima seção irá apresentar os resultados obtidos mediante sua aplicação para a economia da microrregião de Maringá-PR frente ao estado do Paraná, analisando, a seu tempo, os efeitos estrutural, diferencial, alocação e a variação líquida total por setores da indústria de transformação e geral, no entanto, anteriormente, faz-se necessária a caracterização da região em análise bem como a descrição dos procedimentos metodológicos.

\subsubsection{Caracterização da região em análise}

A Microrregião de Maringá - MRM é uma das microrregiões do estado brasileiro do Paraná, pertencente à Mesorregião Norte Central Paranaense. Sua População foi estimada em 2009 pelo Instituto Brasileiro de Geografia e Estatística IBGE em 521.544 habitantes e está dividida em cinco municípios: Mandaguari, Marialva, Maringá, Paiçandu e Sarandi Possui uma área total de 1.573,27 km² e uma densidade populacional de $331,5 \mathrm{hab} . / \mathrm{Km}^{2}$.

Tabela 1 - População e PIB per capta da Microrregião de Maringá

\begin{tabular}{c|c|c|c}
\hline \multirow{2}{*}{ MUNICÍPIO } & $\begin{array}{c}\text { POPULAÇÃO } \\
\text { ESTIMADA (2009) }\end{array}$ & $\begin{array}{c}\text { PIB/HAB R\$ } \\
\text { (EM 2007) }\end{array}$ & $\begin{array}{c}\text { PESSOAL OCUPADO TOTAL } \\
(2008)\end{array}$ \\
\hline Mandaguari & 33.109 & 10.203 & 8.147 \\
Marialva & 31.397 & 11.025 & 6.634 \\
Maringá & 335.511 & 18.914 & 140.981 \\
Paiçandu & 36.876 & 5.766 & 3.590 \\
Sarandi & 84.651 & 5.658 & 12.005 \\
Total & $\mathbf{5 2 1 . 5 4 4}$ & $\mathbf{1 4 . 3 7 1 , 6 0}$ & $\mathbf{1 7 1 . 3 5 7}$ \\
\hline
\end{tabular}

Fonte: IBGE Cidades@

A Tabela 1 mostra que, da população total estimada na microrregião, a cidade de Maringá concentra 64,3\% e as menores concentrações populacionais estão nas cidades de Marialva e Mandaguari com 6,02\% e 6,35\%, respectivamente. Considerando o total do pessoal ocupado, Maringá representa $82 \%$ do total da microrregião e a cidade menos representativa neste quesito é a de Paiçandu. 
Segundo o Atlas do Desenvolvimento Humano no Brasil, desenvolvido pelo Programa das Nações Unidas para o Desenvolvimento - PNUD e o Instituto de Pesquisa Econômica e Aplicada - IPEA, à exceção de Marialva, os municípios da MRM apresentam elevada taxa de urbanização. O município de Maringá apresenta a maior renda per capita, quase o dobro da renda per capita da MRM. Outrossim, afora a cidade de Maringá, as cidades da MRM apresentam um percentual de pobreza acima de $20 \%$, como mostra a Tabela 2 .

Tabela 2 - Área, urbanização e renda na MRM - 2000

\begin{tabular}{l|c|c|c|c|c|c|c}
\hline MUNICÍPIO & ÁREA KM & HAB/ KM 2 & $\begin{array}{c}\text { TAXA DE } \\
\text { URB. }\end{array}$ & $\begin{array}{c}\text { RENDA PER } \\
\text { CAPITA } \\
\text { (R\$ DE 2000) }\end{array}$ & $\begin{array}{c}\text { \% DE } \\
\text { POBRES } \\
(2000)^{*}\end{array}$ & $\begin{array}{c}\text { ÍNDICE } \\
\text { DE GINI }\end{array}$ & $\begin{array}{c}\text { IDH } \\
\text { MUNICIPAL }\end{array}$ \\
\hline Mandaguari & 336,0 & 93,3 & $91,1 \%$ & 238,90 & 22,4 & 0,500 & 0,791 \\
Marialva & 476,4 & 60,3 & $77,0 \%$ & 304,80 & 21,1 & 0,580 & 0,784 \\
Maringá & 490,9 & 587,6 & $98,4 \%$ & 465,40 & 8,3 & 0,560 & 0,841 \\
Paiçandu & 171,0 & 179,7 & $96,3 \%$ & 182,20 & 23,1 & 0,430 & 0,642 \\
Sarandi & 104,3 & 684,5 & $97,3 \%$ & 187,10 & 20,6 & 0,430 & 0,768 \\
\hline
\end{tabular}

Fonte: Atlas do Desenvolvimento Humano no Brasil - PNUD/IPEA

Nota: * Proporção de pessoas com renda domiciliar per capta inferior a $\mathrm{R} \$ 75,50$, equivalente à metade do salário mínimo vigente em agosto de 2000.

As cidades de Paiçandu e Sarandi apresentam os melhores índices no que tange à desigualdade de renda, no entanto, não obstante o conjunto da MRM apresentar um Índice de Desenvolvimento Humano - IDH elevado, os dados municipais revelam que à exceção de Maringá, todos os municípios da MRM possuem IDH Municipal médio (entre 0,500 e 0,799), como mostra a tabela 2.

\subsubsection{Estrutura industrial e emprego formal no PR e MRM.}

Os dados da Relação Anual de Informações Sociais - RAIS, para o ano de 2008, indicaram a presença de 565.644 estabelecimentos no Paraná, os quais eram responsáveis pela geração de 2.503.927 empregos formais.

Na indústria de transformação do Paraná estão concentrados 9,6\% do total dos estabelecimentos e esta indústria é responsável por um a cada quatro empregos formais (23,9\%) do estado. Na MRM estão concentrados 6,1\% do total de estabelecimentos e 5,8\% do total do emprego formal do estado do Paraná. No que tange a indústria de transformação a MRM concentra 7,8\% do total dos estabelecimentos e 6,3\% dos empregos formais.

Na indústria de transformação da MRM mais de $2 / 3$ (66,5\%) dos estabelecimentos estão concentrados em cinco divisões da Classificação Nacional de Atividade Econômica - CNAE: confecções de artigos do vestuário e acessórios (28,4\%); fabricação de produtos alimentícios e bebidas (11,6\%); fabricação de móveis e indústrias diversas (11,3\%); fabricação de produtos de metal (exclusive máquinas e equipamentos) (8,9\%) e edição, impressão e reprodução de gravações (6,3\%).

Considerando os números na esfera estadual, os setores supracitados também concentram mais de 2/3 dos estabelecimentos da indústria de transformação, conforme mostra a Tabela 3. 
Tabela 3 - Relação entre o número de estabelecimentos e empregos na indústria de transformação do Paraná e da MRM - 2008

\begin{tabular}{|c|c|c|c|c|c|c|c|c|}
\hline $\begin{array}{l}\text { Paraná e Microrregião de Maringá } \\
\text { Divisões da CNAE 95 - RAIS 2008 }\end{array}$ & $\begin{array}{l}\text { MRM } \\
\text { Est. }\end{array}$ & $\%$ & $\begin{array}{c}\text { MRM } \\
\text { Emprego } \\
\end{array}$ & $\%$ & $\begin{array}{l}\text { Paraná } \\
\text { Estab. }\end{array}$ & $\%$ & $\begin{array}{c}\text { Paraná } \\
\text { Emprego }\end{array}$ & $\%$ \\
\hline Fabricação de produtos alimentícios e bebidas & 489 & 11,6 & 9.299 & 24,8 & 8.755 & 16,1 & 155.615 & 26,0 \\
\hline Fabricação de produtos do fumo & 2 & 0,0 & 25 & 0,1 & 50 & 0,1 & 834 & 0,1 \\
\hline Fabricação de produtos têxteis & 166 & 3,9 & 1.603 & 4,3 & 1.698 & 3,1 & 14.719 & 2,5 \\
\hline Confecção de artigos do vestuário e acessórios & 1.203 & 28,4 & 8.089 & 21,6 & 8.694 & 16,0 & 70.333 & 11,7 \\
\hline $\begin{array}{l}\text { Preparação de couros e fabrç. de artefatos de } \\
\text { couro, artigos de... }\end{array}$ & 113 & 2,7 & 757 & 2,0 & 1.041 & 1,9 & 7.412 & 1,2 \\
\hline Fabricação de produtos de madeira & 93 & 2,2 & 496 & 1,3 & 4.634 & 8,5 & 40.804 & 6,8 \\
\hline $\begin{array}{l}\text { Fabricação de celulose, papel e produtos de } \\
\text { papel }\end{array}$ & 56 & 1,3 & 338 & 0,9 & 754 & 1,4 & 18.736 & 3,1 \\
\hline Edição, impressão e reprodução de gravações & 268 & 6,3 & 1.213 & 3,2 & 3.917 & 7,2 & 17.682 & 3,0 \\
\hline $\begin{array}{l}\text { Fabrç. de coque, refino de petróleo, elaboração } \\
\text { de combustíveis }\end{array}$ & 7 & 0,2 & 192 & 0,5 & 75 & 0,1 & 17.248 & 2,9 \\
\hline Fabricação de produtos químicos & 107 & 2,5 & 865 & 2,3 & 1.650 & 3,0 & 21.352 & 3,6 \\
\hline Fabricação de artigos de borracha e plástico & 158 & 3,7 & 2.069 & 5,5 & 1.938 & 3,6 & 27.145 & 4,5 \\
\hline $\begin{array}{l}\text { Fabricação de produtos de minerais não } \\
\text { metálicos }\end{array}$ & 152 & 3,6 & 1.184 & 3,2 & 3.256 & 6,0 & 24.400 & 4,1 \\
\hline Metalurgia básica & 65 & 1,5 & 371 & 1,0 & 662 & 1,2 & 6.861 & 1,1 \\
\hline $\begin{array}{l}\text { Fabricação de produtos de metal - exclusive } \\
\text { máquinas e equipamentos }\end{array}$ & 375 & 8,9 & 1.858 & 5,0 & 5.870 & 10,8 & 34.257 & 5,7 \\
\hline Fabricação de maquinas e equipamentos & 211 & 5,0 & 1.845 & 4,9 & 2.737 & 5,0 & 33.204 & 5,5 \\
\hline $\begin{array}{l}\text { Fabrç. de maquinas para escritório e } \\
\text { equipamentos de informática. }\end{array}$ & 9 & 0,2 & 27 & 0,1 & 98 & 0,2 & 4.672 & 0,8 \\
\hline $\begin{array}{l}\text { Fabricação de maquinas, aparelhos e materiais } \\
\text { elétricos }\end{array}$ & 67 & 1,6 & 1.608 & 4,3 & 794 & 1,5 & 14.250 & 2,4 \\
\hline $\begin{array}{l}\text { Fabrç. de material eletrônico e de aparelhos e } \\
\text { equipamentos. }\end{array}$ & 15 & 0,4 & 308 & 0,8 & 254 & 0,5 & 6.287 & 1,0 \\
\hline $\begin{array}{l}\text { Fabrç. de equipamentos de instrumentação } \\
\text { para usos médico-hospitalares }\end{array}$ & 36 & 0,9 & 201 & 0,5 & 494 & 0,9 & 3.047 & 0,5 \\
\hline $\begin{array}{l}\text { Fabrç. e montagem de veículos automotores, } \\
\text { reboques e carrocerias }\end{array}$ & 109 & 2,6 & 1.798 & 4,8 & 785 & 1,4 & 34.937 & 5,8 \\
\hline $\begin{array}{l}\text { Fabricação de outros equipamentos de } \\
\text { transporte }\end{array}$ & 17 & 0,4 & 117 & 0,3 & 236 & 0,4 & 2.234 & 0,4 \\
\hline Fabricação de moveis e industrias diversas & 478 & 11,3 & 3.088 & 8,2 & 5.376 & 9,9 & 41.310 & 6,9 \\
\hline Reciclagem & 34 & 0,8 & 139 & 0,4 & 503 & 0,9 & 1.986 & 0,3 \\
\hline Total & 4230 & 100 & 37490 & 100 & 54271 & 100 & 599.325 & 100 \\
\hline
\end{tabular}

Fonte: RAIS/MTE 2008

Na indústria de transformação da MRM, mais de 2/3 dos empregos estão concentrados em apenas cinco divisões da CNAE: Fabricação de produtos alimentícios e bebidas (24,8\%);confecções de artigos do vestuário e acessórios (21,6\%); fabricação de móveis e indústrias diversas (8,2\%); fabricação de artigos de borracha e plástico (5,5\%) e fabricação de máquinas e equipamentos (4,9\%). Em termos estaduais, o emprego formal da indústria de transformação está concentrado em cinco divisões da CNAE onde estão empregados quase $60 \%$ dos trabalhadores: fabricação de produtos alimentícios e bebidas (26,0\%); confecção de artigos do vestuário e acessórios (11,7\%); fabricação de móveis e indústrias diversas (6,9\%); fabricação de produtos de madeira $(6,8 \%)$ e fabricação de montagem de veículos automotores, reboques e carrocerias $(5,8 \%)$.

Depois de caracterizada a microrregião em análise, bem como a estrutura do emprego nos principais setores da indústria de transformação da MRM frente ao estado do Paraná, a próxima seção será dedicada a apresentação dos resultados referentes a utilização do método estrutural-diferencial. 


\section{Resultados e Discussão}

Constatou-se que o crescimento total do emprego na indústria de transformação na MRM foi de $145 \%$, superior ao crescimento total do emprego na indústria de transformação no estado do Paraná que foi de 104\%. Os setores que mais contribuíram para este crescimento foram: fabricação de produtos alimentícios e bebidas que gerou 5.662 empregos no período e confecção de artigos do vestuário e acessórios que gerou 5.178 empregos no período em análise.

O método estrutural diferencial permite constatar se a MRM está ou não está especializando-se em setores dinâmicos na esfera estadual (estrutural) e também quais as vantagens locacionais da MRM, ou seja, quais os setores que crescem mais na região do que no estado, seja a região dinâmica ou não (diferencial).

Em resumo, a diferença entre o crescimento efetivo da MRM e seu crescimento "teórico" (se a região crescesse à mesma taxa de crescimento do estado) decorre de dois fatores: estrutural (variações de produtividade, padrões de consumo e progresso tecnológico) e o diferencial (vantagens locacionais, qualidade de mão-de-obra, mercado interno e recursos naturais).

Para a análise da MRM frente ao estado do Paraná utilizou-se os dados de emprego na indústria de transformação da RAIS de 1994 e 2008. A Tabela 4 apresenta os resultados da aplicação do método estrutural-diferencial adaptado por Herzog e Olsen (1977).

Tabela 4 - Resultados da aplicação do método estrutural-diferencial na MRM $1994 / 2008$

\begin{tabular}{|c|c|c|c|c|}
\hline Ramo da Indústria & $\begin{array}{c}\text { Efeito } \\
\text { estrutural }\end{array}$ & $\begin{array}{c}\text { Efeito } \\
\text { diferencial }\end{array}$ & $\begin{array}{c}\text { Efeito } \\
\text { Alocação }\end{array}$ & VLT \\
\hline Fabricação de produtos alimentícios e bebidas & 1713 & 207 & -39 & 1881 \\
\hline Fabricação de produtos do fumo & -22 & -103 & 124 & -2 \\
\hline Fabricação de produtos têxteis & -732 & 129 & 658 & 55 \\
\hline Confecção de artigos do vestuário e acessórios & 3843 & -607 & -1084 & 2151 \\
\hline Preparação de couros e Fabrç. de artefatos de couro, artigos de... & -440 & 135 & 48 & -257 \\
\hline Fabricação de produtos de madeira & -498 & 32 & -15 & -481 \\
\hline Fabricação de celulose, papel e produtos de papel & -22 & -435 & 749 & 291 \\
\hline Edição, impressão e reprodução de gravações & 70 & 231 & 116 & 418 \\
\hline Fabricação de produtos químicos & -25 & 302 & -128 & 149 \\
\hline Fabricação de artigos de borracha e plástico & 294 & -76 & 982 & 1200 \\
\hline Fabricação de produtos de minerais não metálicos & -199 & 422 & 191 & 413 \\
\hline Metalurgia básica & -350 & -610 & 236 & -724 \\
\hline Fabricação de produtos de metal - exclusive maquinas e equipamentos & 526 & -34 & 11 & 504 \\
\hline Fabricação de maquinas e equipamentos & -87 & 72 & 1099 & 1084 \\
\hline Fabrç. de maquinas para escritório e equipamentos de informática & 93 & -1995 & 1905 & 3 \\
\hline Fabricação de maquinas, aparelhos e materiais elétricos & -347 & 170 & 151 & -26 \\
\hline Fabrç. de material eletrônico e de aparelhos e equipamentos & 545 & -1134 & 630 & 41 \\
\hline Fabrç. de equipamentos de instrumentação para usos médico-hospitalar & 101 & 2 & 0 & 103 \\
\hline Fabrç. e montagem de veículos automotores, reboques e carrocerias & 752 & -956 & 401 & 197 \\
\hline Fabricação de outros equipamentos de transporte & 7 & -192 & 79 & -105 \\
\hline Fabricação de moveis e indústrias diversas & -131 & -848 & 127 & -853 \\
\hline Reciclagem & 36 & -191 & 280 & 125 \\
\hline TOTAL INDÚSTRIA & 5126 & -5480 & $\mathbf{0}$ & 6166 \\
\hline
\end{tabular}


Fonte: Dados brutos da RAIS 1994/ 2008

O efeito estrutural apresentou sinal negativo em alguns setores como preparação de couros (-440), fabricação de produtos de madeira (-498), fabricação de produtos têxteis (-732) e metalurgia básica (-350).

No entanto, o efeito estrutural total da indústria de transformação na MRM foi positivo (5126), influenciado principalmente pela fabricação de produtos alimentícios e bebidas (1713) e pela confecção de artigos do vestuário e acessórios (3843), o que significa que estes são dinâmicos na indústria de transformação paranaense e estão bem representados na MRM. Estas informações podem ser visualizadas no Gráfico 1.

Gráfico 1 - Efeito estrutural MRM 1994/ 2008

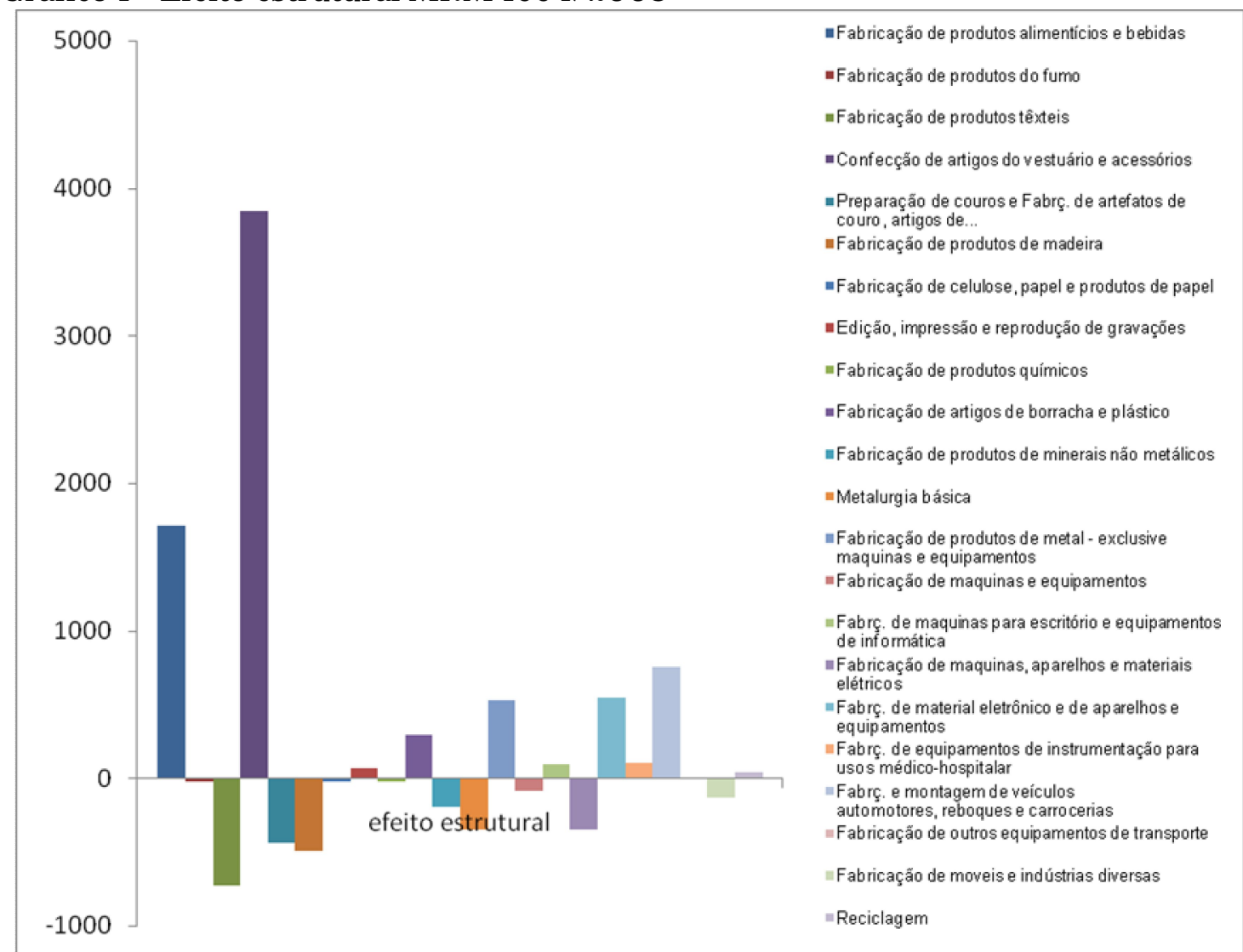

Fonte: Tabela 4.

O efeito diferencial ou competitivo total foi negativo (-5480) para a MRM, o que indica que a indústria de transformação nessa microrregião cresceu a uma taxa média inferior à taxa média do estado.

Os Setores que mais contribuíram para o resultado negativo foram: a fabricação de máquinas para escritório e equipamentos de informática (-1995); a fabricação de material eletrônico, de aparelhos e equipamentos (-1134); a fabricação e montagem de veículos automotores (-956) e a fabricação de móveis e indústrias diversas (-848).

No entanto, analisando cada setor individualmente, vários deles encontram-se com sinal positivo como Fabricação de produtos alimentícios e bebidas (207) e 
fabricação de produtos têxteis (129), que são reconhecidamente setores de grande pujança na região de Maringá. Estas informações estão apresentadas no Gráfico 2.

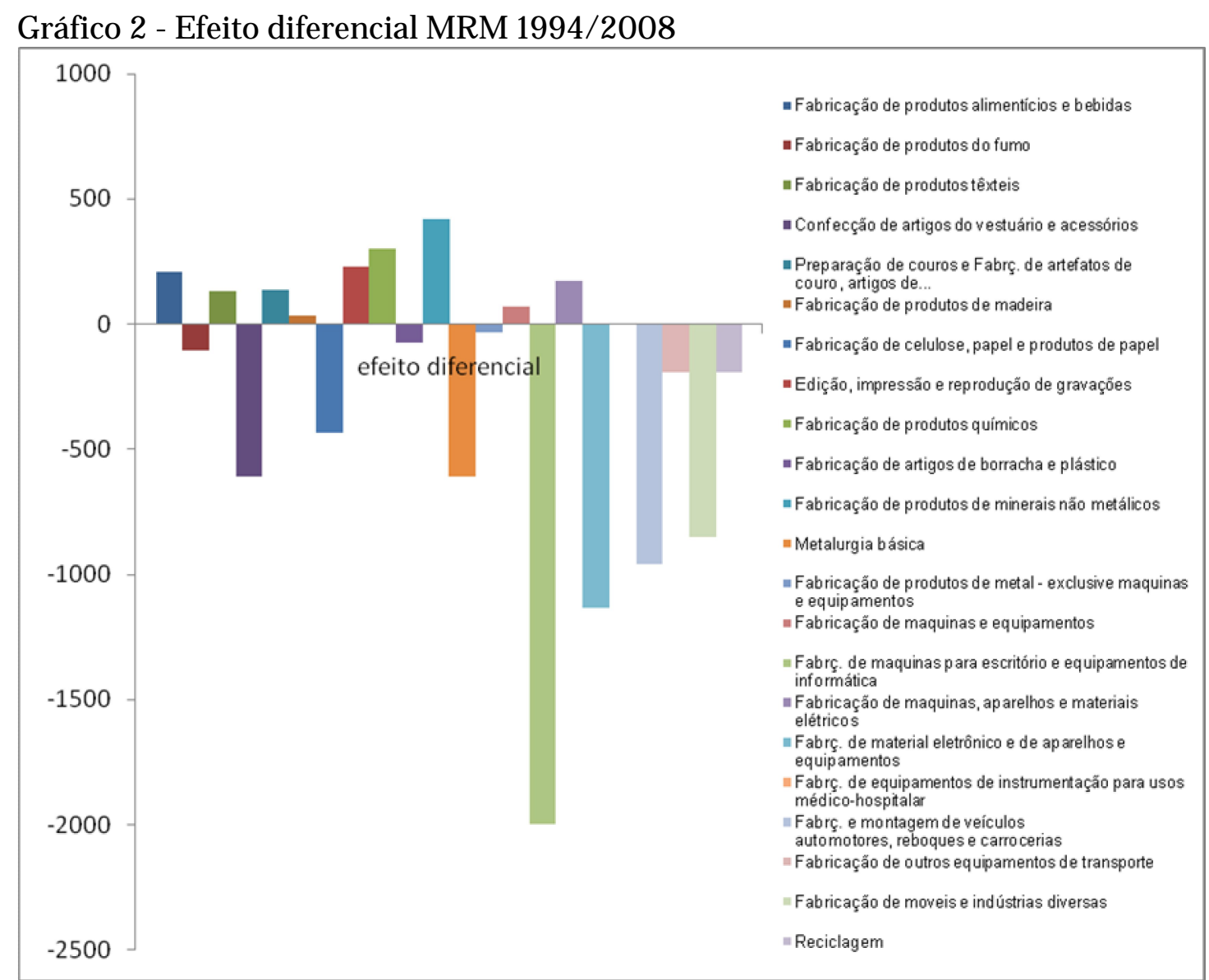

Fonte: Tabela 4.

A análise do efeito alocação só tem sentido pelo exame de suas parcelas, conforme os parâmetros estabelecidos pelo Quadro 1, onde são consideradas a especialização e a vantagem competitiva da região em comparação com o estado do Paraná. A Tabela 5 apresenta os resultados desta análise, onde a classificação pode ser definida como: Vantagem Competitiva Especializada - VCE; Desvantagem Competitiva Especializada - DCE; Vantagem Competitiva não Especializada - VCNE; Desvantagem Competitiva não Especializada - DCNE. 
Tabela 5 - Efeito alocação e suas parcelas para a MRM 1994/ 2008

\begin{tabular}{|c|c|c|c|c|}
\hline Ramo da Indústria & $\begin{array}{c}\text { Alocação } \\
\text { total }\end{array}$ & $\begin{array}{c}\text { Especia- } \\
\text { lização }\end{array}$ & $\begin{array}{c}\text { Vantagem } \\
\text { compe- } \\
\text { titiva }\end{array}$ & Definição \\
\hline Fabrç. de maquinas para escritório e equipamentos de informática & $(+)$ & $(-)$ & $(-)$ & DCNE \\
\hline Fabricação de maquinas e equipamentos & $(+)$ & $(+)$ & $(+)$ & VCE \\
\hline Fabricação de artigos de borracha e plástico & $(+)$ & $(+)$ & $(+)$ & VCE \\
\hline Fabricação de celulose, papel e produtos de papel & $(+)$ & $(+)$ & $(+)$ & VCE \\
\hline Fabricação de produtos têxteis & $(+)$ & $(+)$ & $(+)$ & VCE \\
\hline Fabrç. de material eletrônico e de aparelhos e equipamentos & $(+)$ & $(-)$ & $(-)$ & DCNE \\
\hline Fabrç. e montagem de veículos automotores, reboques e carroceria & $(+)$ & $(-)$ & $(-)$ & DCNE \\
\hline Reciclagem & $(+)$ & $(+)$ & $(+)$ & VCE \\
\hline Metalurgia básica & $(+)$ & $(-)$ & $(-)$ & DCNE \\
\hline Fabricação de produtos de minerais não metálicos & $(+)$ & $(+)$ & $(+)$ & $\mathrm{VCE}$ \\
\hline Fabricação de maquinas, aparelhos e materiais elétricos & $(+)$ & $(+)$ & $(+)$ & VCE \\
\hline Fabricação de moveis e indústrias diversas & $(+)$ & $(-)$ & $(-)$ & DCNE \\
\hline Fabricação de produtos do fumo & $(+)$ & $(+)$ & $(+)$ & VCE \\
\hline Edição, impressão e reprodução de gravações & $(+)$ & $(+)$ & $(+)$ & VCE \\
\hline Fabricação de outros equipamentos de transporte & $(+)$ & $(-)$ & $(-)$ & DCNE \\
\hline Preparação de couros e fabrç. de artefatos de couro & $(+)$ & $(+)$ & $(+)$ & VCE \\
\hline Fabricação de produtos de metal - exclusive máquinas e equipamentos & $(+)$ & $(-)$ & $(-)$ & DCNE \\
\hline Fabrç. de equipamentos de instrumentação para usos médico-hospitalar & $(+)$ & $(+)$ & $(+)$ & VCE \\
\hline Fabricação de produtos de madeira & $(-)$ & $(-)$ & $(+)$ & VCNE \\
\hline Fabricação de produtos alimentícios e bebidas & $(-)$ & $(-)$ & $(+)$ & VCNE \\
\hline Fabricação de produtos químicos & $(-)$ & $(-)$ & $(+)$ & VCNE \\
\hline Confecção de artigos do vestuário e acessórios & $(-)$ & $(+)$ & $(-)$ & DCE \\
\hline
\end{tabular}

Fonte: Dados brutos da RAIS 1994/ 2008.

A MRM apresentou vantagem competitiva especializada nos setores de fabricação de máquinas e equipamentos; produtos de borracha; celulose e produtos de papel; produtos têxteis; reciclagem; produtos minerais não metálicos; máquinas e materiais elétricos; fumo; edição e impressão; artefatos de couro; equipamentos médico-hospitalares, isso significa que a MRM é especializada nos setores mencionados e que estes setores crescem mais na região que no estado.

A microrregião também apresentou desvantagem competitiva não especializada em alguns setores como a produção de: máquinas para escritório e equipamentos de informática; material eletrônico; montagem de veículos automotores; metalurgia básica; móveis; equipamentos de transporte e produtos de metal (exclusive máquinas e equipamentos), isto mostra que a MRM não é especializada nestes setores e que estes setores crescem menos na MRM do que no estado.

O Gráfico 3 apresenta o comportamento do efeito alocação para cada setor da indústria de transformação na MRM. 
Gráfico 3 - Efeito alocação MRM 1994/ 2008

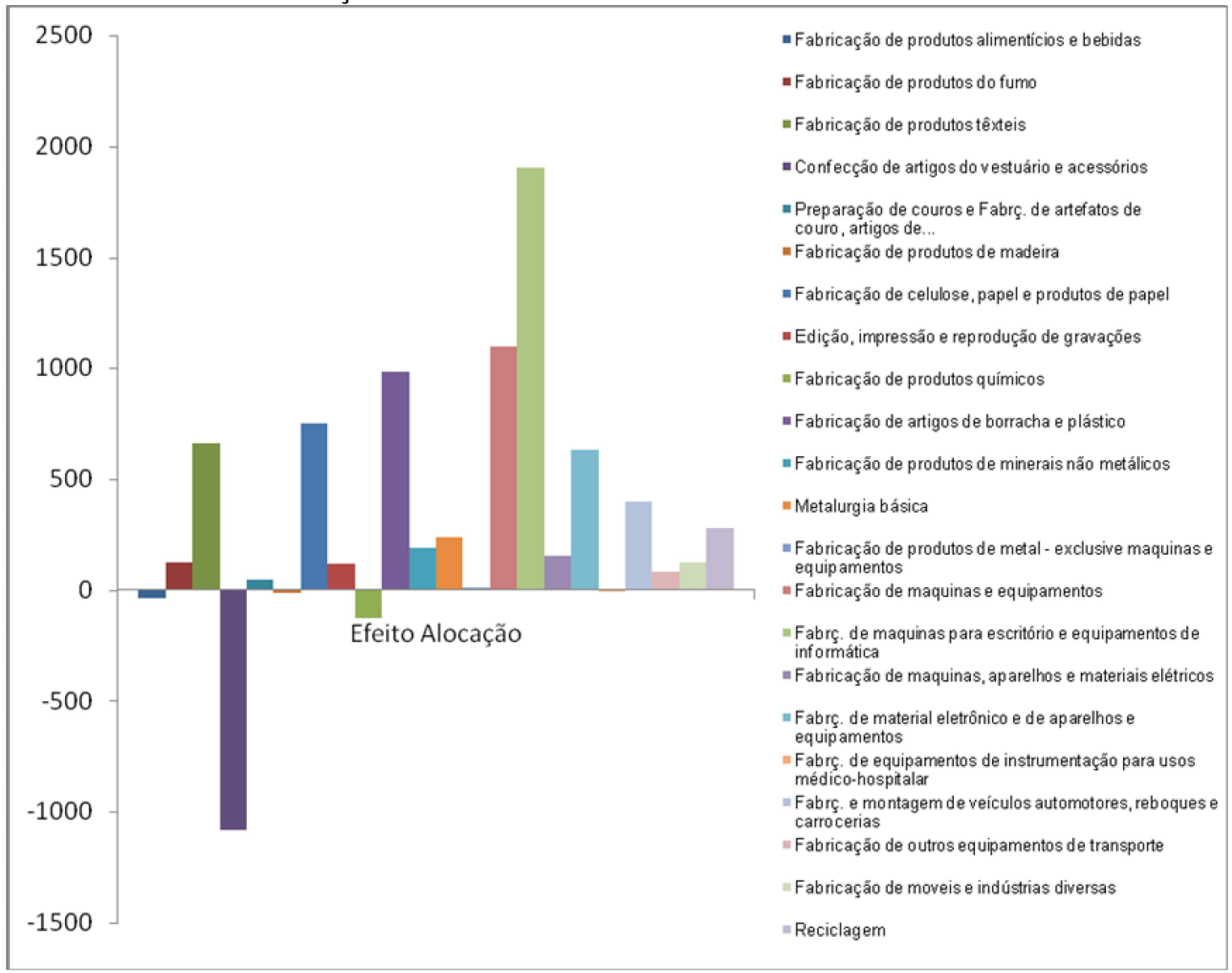

Fonte: Tabela 4.

A Variação Líquida Total - VLT consiste na soma entre a variação estrutural, a variação diferencial e o efeito alocação, essa análise reflete o montante líquido da variável base, no caso o emprego de cada setor entre o período inicial e final. Se a VLT é negativa indica que o setor perdeu empregos líquidos interperíodos, se a VLT for positiva indica que o setor ganhou empregos interperíodos.

A VLT para o total da MRM entre os anos de 1994 e 2008 foi positiva (11.484) o comportamento de cada setor pode ser visualizado no Gráfico 4. 
Gráfico 4 - Variação Líquida Total MRM 1994/ 2008

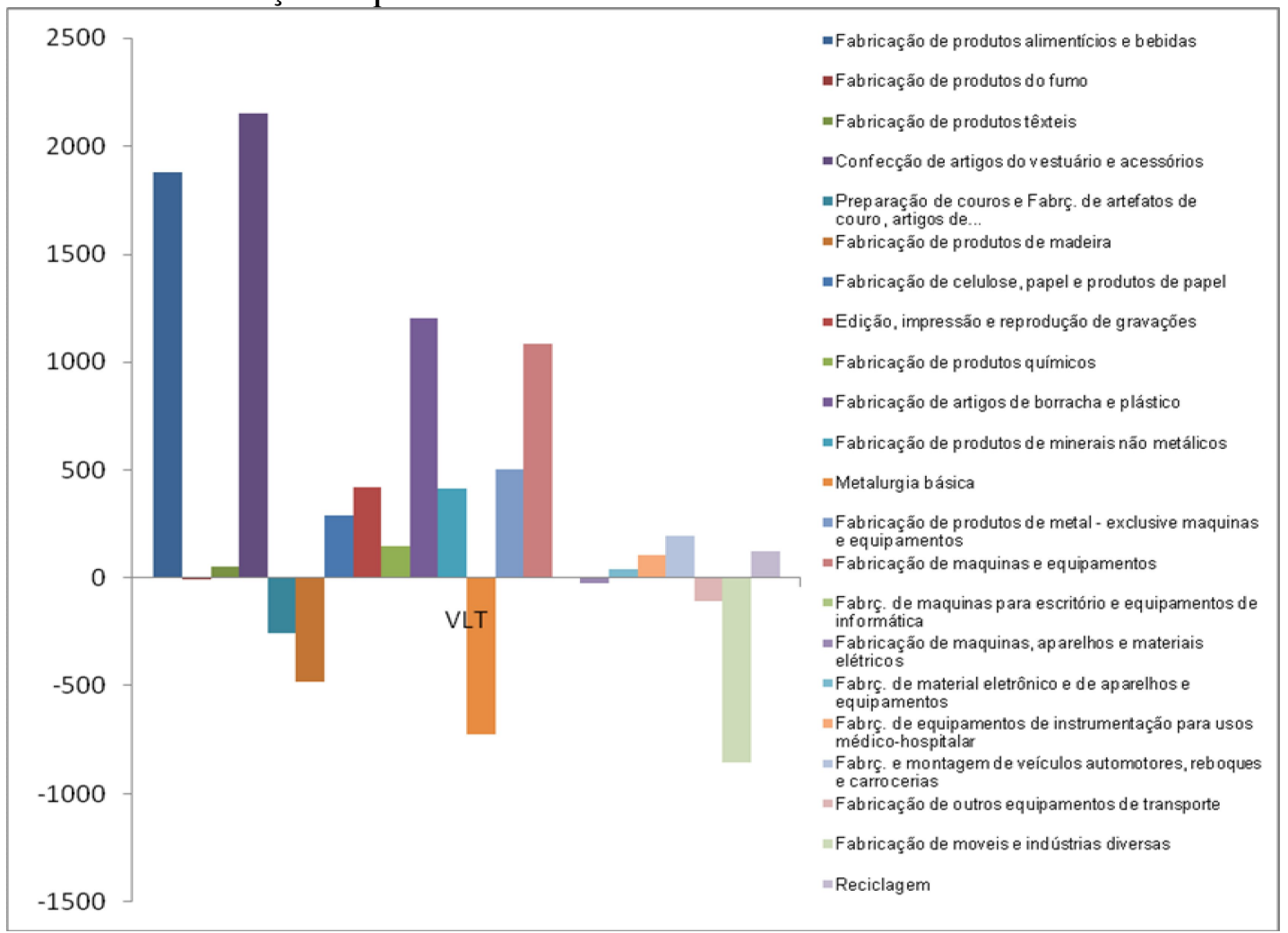

Fonte: Tabela 4

A variação líquida total da variável base (emprego) na microrregião foi positiva principalmente devido aos setores: fabricação de produtos alimentícios e bebidas, confecção de artigos do vestuário, fabricação de artigos de borracha e plástico e fabricação de máquinas e equipamentos.

\section{Considerações Finais}

A microrregião de Maringá é formada por cinco municípios, no entanto, os fatores de produção, trabalho e capital, estão concentrados na cidade de Maringá. A cidade concentra $64 \%$ da população total, $82 \%$ do pessoal ocupado e apresenta o menor percentual de pobreza com apenas $8 \%$ da população com renda per capta inferior a $\mathrm{R} \$ 75,00 /$ mês.

O emprego na indústria de transformação da MRM cresceu mais que a média da indústria de transformação no estado do Paraná. O efeito estrutural total foi positivo, principalmente devido aos setores de produção de alimentos e bebidas e da confecção de artigos do vestuário e acessórios, o que mostra que estes setores são dinâmicos na esfera estadual e estão bem representados na MRM.

A MRM apresentou sinais negativos para o efeito diferencial em vários setores, principalmente para a fabricação de máquinas para escritório e equipamentos de informática, a fabricação de material eletrônico e a fabricação e montagem de veículos automotores. Esta questão precisa ser verificada com cuidado, pois nesses setores o crescimento foi menor que a média do estado e como pode-se perceber são 
setores de alta tecnologia que têm desdobramentos em outros setores, não só da indústria mas também da agricultura e prestação de serviços.

A MRM mostrou-se especializada e com vantagens competitivas em vários setores da indústria de transformação além de apresentar uma variação líquida total do emprego positiva, o que significa que a microrregião ganhou empregos líquidos no período em análise.

O método estrutural-diferencial é descritivo e não tem como objetivo explicar o "porquê" alguns setores crescem mais que outros, no entanto, as conclusões expostas neste trabalho podem servir para posteriores análises e condução de políticas públicas no sentido de dar atenção a setores estratégicos que não estão crescendo como deveriam, além de potencializar os setores onde a MRM já apresenta vantagens estruturais e diferenciais.

\section{Referências}

ALBUQUERQUE, J . J . L. \& PINHEIRO, A.A.P. Análise do desempenho agrícola de duas micro-regiões do sertão central (ceará), através do modelo estrutural diferencial. Ciência Agronômica, v. 10, noำ, p. 99-101, jan./jun., 1980. Fortaleza - Ceará.

AZZONI, C.R. Concentração Regional e Dispersão das Rendas Per Capta Estaduais: Análise a partir de Séries Históricas Estaduais do PIB 19391995. Estudos Econômicos São Paulo, V27, n3, p 341-393, Set-dez 1997.

BRASIL, Ministério do Trabalho e Emprego: Relação Anual de Informações Sociais - RAIS. CD/ DVD Base de Dados de 1994 a 2008. Brasília, DF.

CANUTO, O. \& XAVIER. C. L. Padrões de especialização e competitividade no comércio exterior brasileiro: uma análise estrutural-diferencial. Texto para discussão IE/ UNICAMP no 86, out. 1999(a)

CANUTO, O. \& XAVIER. C. L. Padrões de especialização e competitividade no comércio exterior brasileiro: uma análise estrutural-diferencial. Revista Paranaense de Desenvolvimento, Curitiba, no 97, p. 33-47, set./ dez. 1999(b).

CAVALCANTE, A.; CROCCO, M. e BRITO, M. A. de. Impactos macroeconômicos da variação regional da oferta de crédito. In: Associação Nacional dos Cursos de Pós-Graduação em Economia. Disponível em: www.anpec.org.br/ encontro2005/ artigos/ ao5a121.pdf

ESTEBAN-MARQUILLAS, J. M. Shift-share analysis revisited. Regional anda Urban Economics, v. 2. № 3, p. 249-261, 1972.

FEISTEL, P. R. e ABREU, M. P. Composição das exportações dos estados da região sul do Brasil: uma aplicação do método shift-share. In: $5^{\circ}$ Encontro da Economia Gaúcha, 2010, Porto Alegre. 5o Encontro da Economia Gaucha, 2010.

FERREIRA, M. de N. C. e MENDES, F. A. T. Impactos do fundo constitucional de financiamento do norte (FNO) sobre a agricultura paraense - 1990 a 
1999. Congresso Brasileiro da Sociedade Brasileira de Economia, Administração e Sociologia Rural, J uiz de Fora, Brasil - 2003.

HADDAD, P.R. (Org.). Economia regional: teorias e métodos de análise. Fortaleza: Banco do Nordeste do Brasil, 1989.

HERZOG, H. W. \& OSLEN, R. J. Shift-share analysis revisited: the allocation effect and the stability of regional structure. J ournal of Regional Science, v. 17, noㄴ, p. 441-454, 1977.

IBGE. Instituto Brasileiro de Geografia e Estatística. Base de Dados: IBGE Cidades@. Disponível em www.ibge.gov.br

PNUD - Programa das Nações Unidas para o Desenvolvimento. Atlas do Desenvolvimento Humano no Brasil. (2000). Disponível em www.ipea.gov.br

RIPPEL, R. \& LIMA, J . F. Fatores diferenciais e estruturais na localização e crescimento da população rural no Oeste Paranaense. XVI Encontro Nacional de Estudos Populacionais, ABEP, Caxambu - MG - Brasil, 29/09/ a $03 / 10 / 2008$.

SCALABRIN, I. \& ALVES, T. W. Análise da geração de valor das empresas brasileiras, com ações em bolsa, de 1996 a 2000, utilizando o método estrutural diferencial. UnB Contábil v. 5, no 1 , Departamento de Ciências Contábeis e Atuariais - Universidade de Brasília - UnB. 2002.

SIMÕES, R. Projeto: Diretrizes para formulação de políticas de desenvolvimento regional e de ordenação do território brasileiro. Relatório: Síntese e Reflexão Teórica. Universidade Federal de Minas Gerais. Faculdade de Ciências Econômicas. Centro de Desenvolvimento e Planejamento Regional CEDEPLAR, 2004.

SIMÕES, R.F. Métodos de análise regional e urbana: diagnóstico aplicado ao planejamento. Belo Horizonte: UFMG/CEDEPLAR, 2005, 31p. (Texto para discussão, 259).

SOUZA, N. R. Regiões-chave na integração econômica regional. Análise Econômica, Porto Alegre: FCE/UFRGS, ano 14, no25 e 26, p. 16-24, mar. E set. 1996.

SOUZA, N.J . Desenvolvimento Regional. São Paulo: Atlas, 2009.

STILWELLl, F. J . Regional growth and structural adaptation. Urban Studies, 6 : 16278, 1969. 